\title{
Vapor-Liquid-Solid Growth of Small- and Uniform-Diameter Silicon Nanowires at Low Temperature from $\mathrm{Si}_{2} \mathrm{H}_{6}$
}

\author{
Saeed Akhtar ${ }^{1}$, Koichi Usami ${ }^{1}$, Yoshishige Tsuchiya ${ }^{1,2}$, Hiroshi Mizuta ${ }^{2,3}$, and Shunri Oda ${ }^{1,2 *}$ \\ ${ }_{1}^{1}$ Quantum Nanoelectronics Research Center, Tokyo Institute of Technology, 2-12-1 O-okayama, Meguro-ku, Tokyo 152-8552, Japan \\ 2 Solution Oriented Research for Science and Technology, JST, Kawaguchi, Saitama 332-0012, Japan \\ ${ }^{3}$ School of Electronics and Computer Science, Southampton University, Highfield, Southampton SO17 1BJ, U.K. \\ Received November 12, 2007; accepted December 7, 2007; published online January 11, 2008
}

We report $350^{\circ} \mathrm{C}$ as a critical growth temperature for overcoming the aggregation of gold $(\mathrm{Au})$ in the synthesis of high-density silicon nanowires (SiNWs) with controlled diameters in a vapor-liquid-solid (VLS) mechanism by the low-temperature decomposition of $\mathrm{Si}_{2} \mathrm{H}_{6}$. Low-temperature growth is considered essential for preserving the initial distribution of Au droplets $(8 \pm 5 \mathrm{~nm})$ during SiNW nucleation with small $(12 \mathrm{~nm})$ and uniform $( \pm 5 \mathrm{~nm})$ diameters. Au-Si eutectics increase in size with aggregation at high temperatures, resulting in SiNWs with large and random diameters. The crystal quality, defect formation, and morphology of the wires, grown in the (111) direction, are size dependent. (C) 2008 The Japan Society of Applied Physics

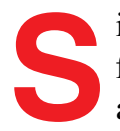
ilicon nanowires (SiNWs) are promising materials for future nanoelectronic and photonic device applications. ${ }^{1,2)}$ SiNWs may also be key components in chemical and biomedical sensors. ${ }^{3,4)}$ The proposed applications have been motivating new research and development of growth technologies for realizing the synthesis of controlled-diameter SiNWs via a vapor-liquid-solid (VLS) mechanism. ${ }^{5,6)}$

Gold $(\mathrm{Au})$ has been commonly used to mediate SiNW growth because the eutectic temperature of bulk $\mathrm{Au}-\mathrm{Si}$ is lower than those of other catalyst systems. However, the aggregation of $\mathrm{Au}$ at elevated temperatures is a major problem when realizing controlled-diameter SiNWs by a VLS technique. ${ }^{7)}$ SiNWs with uniform-diameters have been synthesized using well-defined $\mathrm{Au}$ nanocolloids from $\mathrm{SiH}_{4}$ and $\mathrm{SiCl}_{4}{ }^{8,9)}$ However, high-density SiNWs with fixed diameters cannot be grown from densely packed Au nanocolloids due to aggregation at high growth temperatures. It is also difficult to achieve the uniform dispersion of $\mathrm{Au}$ colloids on the substrate. Furthermore, the low-temperature plasma decomposition of $\mathrm{SiH}_{4}$ has also been performed to grow small-diameter SiNWs. ${ }^{10)}$ By this technique, a radio frequency plasma also enhances the uncatalytical decomposition of the source gas and there is a risk of plasma damage to the SiNWs. Such growth techniques did not yield high-density SiNWs with controlled diameters.

Low-temperature growth is a prerequisite for growing high-density SiNWs with uniform-diameters from dense $\mathrm{Au}$ droplets. We have been performing the low-temperature decomposition of $\mathrm{Si}_{2} \mathrm{H}_{6}$ to grow $\mathrm{SiNWs}$ at low temperatures. ${ }^{11)}$ The synthesis of SiNWs from $\mathrm{Si}_{2} \mathrm{H}_{6}$ has been reported, but growth temperatures could not be reduced below $500{ }^{\circ} \mathrm{C}$, resulting in wires with random diameters $(30-135 \mathrm{~nm})$ due to the agglomeration of Au. ${ }^{12)}$ Whereas the diameter of a single wire does not seem to be fixed. Hence, a further reduction in growth temperature is essential for growing controlled-diameter SiNWs.

In this study, we show that $350{ }^{\circ} \mathrm{C}$ is the critical growth temperature required to overcome the aggregation of $\mathrm{Au}$ for growing high-density SiNWs with small and uniform diameters from densely packed Au droplets. We perform

*E-mail address: soda@pe.titech.ac.jp the low-temperature decomposition of $\mathrm{Si}_{2} \mathrm{H}_{6}$ in a lowpressure chemical vapor deposition (LPCVD) system to achieve such low-temperature growth. We also demonstrate that the structural properties of the SiNWs, such as crystal quality and defect formation, depend on the size of $\mathrm{Au}-\mathrm{Si}$ eutectic droplets and hence the diameter of the wires.

High-density Au droplets were prepared on H-terminated $\mathrm{Si}(111)$ substrates at room temperature (RT) by e-beam evaporation to grow SiNWs. The resistivity of the substrates was $1-1.2 \Omega \cdot \mathrm{cm}$. The equivalent thickness of the $\mathrm{Au}$ film evaluated using a quartz crystal monitor was $0.5 \mathrm{~nm}$. SiNW growth was carried out in an LPCVD chamber by typically exposing the substrates covered by $\mathrm{Au}$ droplets at a $\mathrm{Si}_{2} \mathrm{H}_{6}$ flow rate of $1 \mathrm{sccm}$ and $\mathrm{a}_{2}$ flow rate of $49 \mathrm{sccm}$ at a pressure of 3 Torr after heating to $350^{\circ} \mathrm{C}$. Scanning electron microscopy (SEM) and transmission electron microscopy (TEM) were performed to characterize the wires.

Figure 1 shows SEM images of the Au droplets prepared at RT by e-beam evaporation and those obtained after annealing at 350 and $400{ }^{\circ} \mathrm{C}$ without exposing to the source gas. The average size distribution of the $\mathrm{Au}$ droplets was found to be $8 \pm 5 \mathrm{~nm}$ [Fig. 1(a)]. This distribution almost remains the same $(10 \pm 5 \mathrm{~nm})$ after the formation of $\mathrm{Au}-\mathrm{Si}$ eutectic droplets by annealing at $350{ }^{\circ} \mathrm{C}$ [Fig. 1(b)], where droplets become spherical. We suggest that these molten $\mathrm{Au}-\mathrm{Si}$ eutectics were formed by consuming $\mathrm{Si}$ from the underlying substrate. ${ }^{13,14)}$ However, the size distribution of the $\mathrm{Au}-\mathrm{Si}$ eutectic alloys was adversely affected by annealing at $400{ }^{\circ} \mathrm{C}$, where random and large eutectic islands were formed [Fig. 1(c)]. The coarsening of $\mathrm{Au}$ at higher annealing temperatures has also been reported, ${ }^{7,12)}$ but we observed that this coarsening effect only occurs above $350^{\circ} \mathrm{C}$. These observations suggest that the aggregation of $\mathrm{Au}$ can be suppressed in low-temperature growth.

Figure 2(a) shows the SEM image of a SiNW with a diameter of $8 \mathrm{~nm}$, which indicates that wires grow via VLS mechanism. Figures 2(b)-2(d) show the SEM images of the SiNWs grown at 350,375 , and $400^{\circ} \mathrm{C}$, respectively. In all these cases, the SiNWs were grown by exposing Au droplets covering the $\mathrm{Si}(111)$ substrate to a mixture with a $\mathrm{Si}_{2} \mathrm{H}_{6}$ flow rate of $1 \mathrm{sccm}$ and a $\mathrm{H}_{2}$ flow rate of $49 \mathrm{sccm}$ for $30 \mathrm{~min}$ at 3 Torr. Figure 2(b) shows the high-density SiNWs grown at 


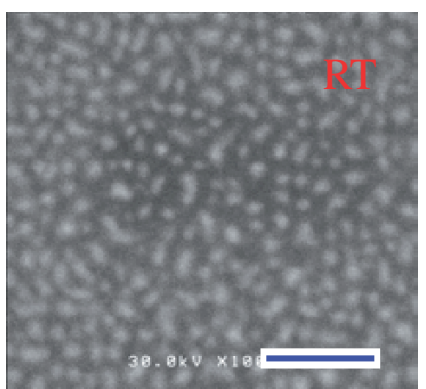

(a)

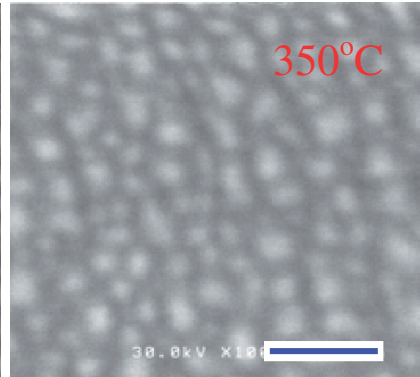

(b)

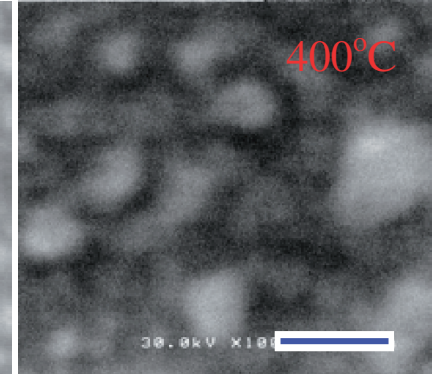

(c)

Fig. 1. SEM images of (a) Au droplets deposited on Si substrate at room temperature by e-beam evaporation, (b) Au-Si eutectics formed after annealing at $350^{\circ} \mathrm{C}$, and (c) Au-Si eutectics formed after annealing at $400^{\circ} \mathrm{C}$. Scale bar in (a)-(c) is $30 \mathrm{~nm}$.

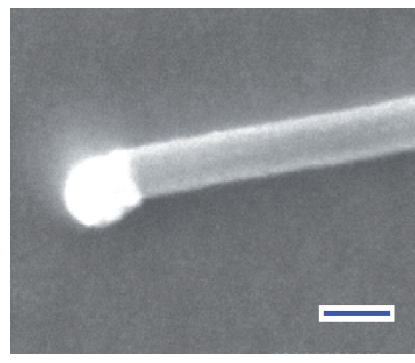

(a)

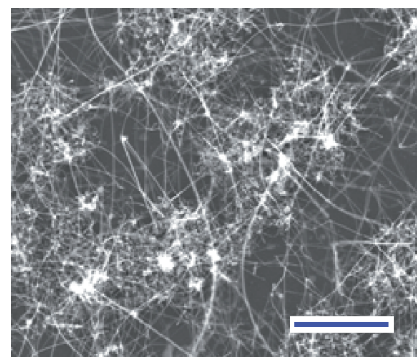

(c)

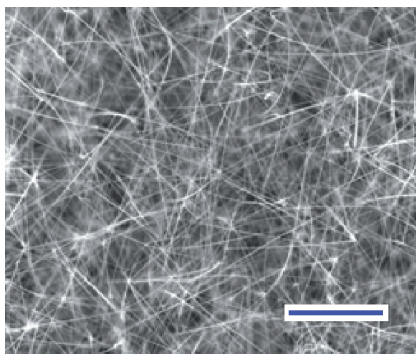

(b)

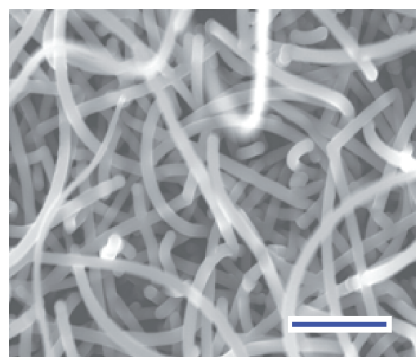

(d)
Fig. 2. SEM images of (a) SiNW showing VLS growth, (b) highdensity SiNWs grown on $\mathrm{Si}(111)$ at $350^{\circ} \mathrm{C}$, (c) SiNWs grown at $375^{\circ} \mathrm{C}$, and (d) SiNWs grown at $400^{\circ} \mathrm{C}$. Scale bar in (a) is $10 \mathrm{~nm}$ and in (b)-(d) is $2 \mu \mathrm{m}$.

$350^{\circ} \mathrm{C}$. The wires were found to be straight and have small and uniform-diameters $(12 \pm 5 \mathrm{~nm})$. The diameters of the wires were observed to be consistent with the sizes of the $\mathrm{Au}$ droplets prepared at RT. Some very long wires showed bending. The effect of the Au aggregation at $375^{\circ} \mathrm{C}$ can be observed in Fig. 2(c), where the SiNWs grow in $5 \times 5 \mu \mathrm{m}$ patches by leaving micron-sized empty spaces around them resulting in a relatively large size distribution (8$40 \mathrm{~nm}$ ). However, at $400{ }^{\circ} \mathrm{C}$, the SiNWs grow in small spheres widely separated from one another with very random and large diameters $(350 \pm 50 \mathrm{~nm})$ due to the aggregation of $\mathrm{Au}$ [Fig. 2(d)]. We observed that $350{ }^{\circ} \mathrm{C}$ is a critical temperature above which the aggregation of $\mathrm{Au}$ adversely affects the diameter distribution of the VLS grown SiNWs.

Figure 3 shows the size distributions of the Au droplets prepared at RT and SiNWs grown at $350{ }^{\circ} \mathrm{C}$. The heights of

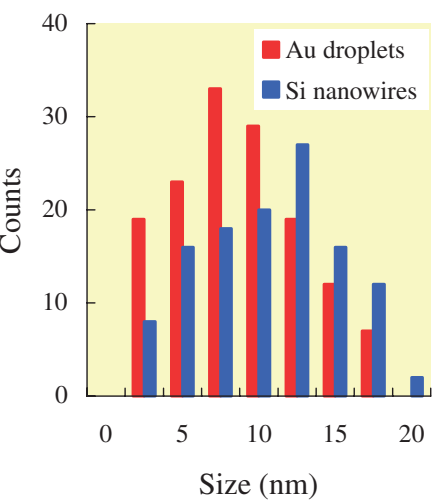

Fig. 3. Size distributions of $A u$ droplets $(8 \pm 5 \mathrm{~nm})$ and SiNWs $(12 \pm 5 \mathrm{~nm})$ prepared at $350^{\circ} \mathrm{C}$.

the lines represent the occurrences of the $\mathrm{Au}$ droplets and SiNWs determined on the basis of SEM results shown in Figs. 1(a) and 2(b). The counts and sizes of the Au droplets can be correlated to those of the SiNWs grown at low temperatures. The size distribution of the SiNWs grown at high temperatures cannot be correlated to that of the $\mathrm{Au}$ droplets prepared at RT.

High-resolution TEM analysis revealed that the structural properties of the SiNWs are size dependent. Figures 4(a) and 4(b) show TEM images of the SiNW grown at $350^{\circ} \mathrm{C}$ with a diameter of about $8 \mathrm{~nm}$. We observed that the SiNWs with small-diameters, grown in (111) as a preferential direction, are straight and have clean side walls [Fig. 4(a)]. Figure 4(b) shows that the wires have a single-crystal defect-free core covered with a very thin surface oxide layer. A high crystal quality ensures better physical properties for small-diameter wires.

However, different types of defect were observed in the SiNWs with increasing diameters grown at $375^{\circ} \mathrm{C}$. A twin boundary appears in the SiNWs with a diameter of about $18 \mathrm{~nm}$ in the form of a slightly visible line without affecting the lattice orientation, as shown in Fig. 5(a) in red. Meanwhile, the SiNWs with a diameter of $20 \mathrm{~nm}$ become bicrystalline and contain a single (111) twin boundary. Figure 5(b) shows the high-resolution TEM image of the bicrystalline SiNWs grown in the (111) direction when viewed down the [110] plane. Bi crystal orientation has been 


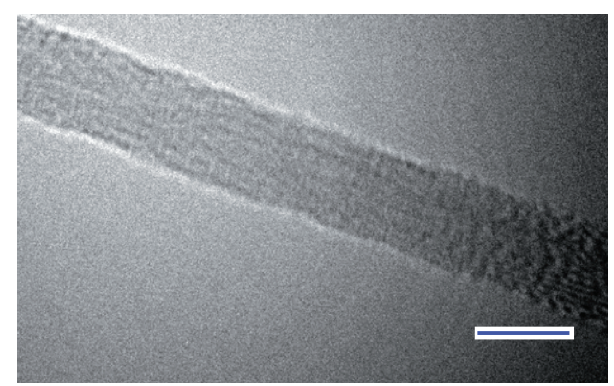

(a)

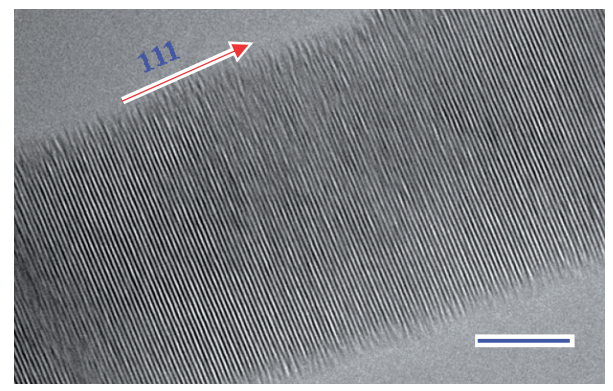

(b)

Fig. 4. (a) Low-resolution TEM image of SiNW with diameter of $8 \mathrm{~nm}$. Scale bar is $10 \mathrm{~nm}$. (b) High-resolution TEM image of same wire grown in (111) direction. Scale bar is $2 \mathrm{~nm}$.

indicated with red lines. Periodic twins were formed in the SiNWs with diameters above $20 \mathrm{~nm}$, transforming the side walls of the wires to have a zig-zag morphology [Figs. 5(c) and 5(d)]. These structural defects were observed in the SiNWs with diameters larger than $17 \mathrm{~nm}$.

In conclusion, we have investigated the effect of substrate temperature by the VLS growth of SiNWs from a $\mathrm{Au}$ catalyst. We have demonstrated that $350{ }^{\circ} \mathrm{C}$ is the critical temperature required to preserve the initial size distribution of high-density $\mathrm{Au}$ droplets during $\mathrm{Au}-\mathrm{Si}$ eutectic alloy formation for growing SiNWs with small and uniform diameters. Such a low temperature has been achieved by the low-temperature decomposition of $\mathrm{Si}_{2} \mathrm{H}_{6}$. High growth temperatures, such as $400^{\circ} \mathrm{C}$, form large and random eutectic droplets by aggregation, which results in the large and random diameters of $\mathrm{Si}$ wires. We have shown that the crystal quality of the wires is size dependent. TEM analysis has revealed that, in contrast to the large wires, SiNWs with small diameters are defect-free and have high-quality singlecrystal cores. Low-temperature-grown SiNWs with small diameters are attractive for SiNW-based electronic and photonic device applications because defect-free wires ensure good physical properties.

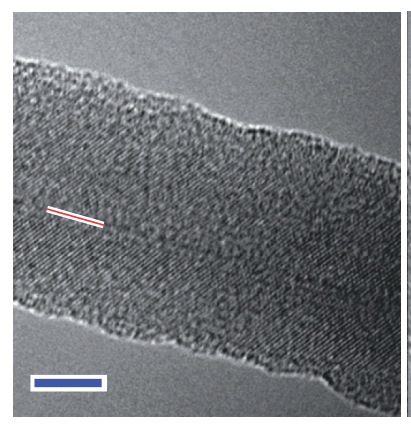

(a)

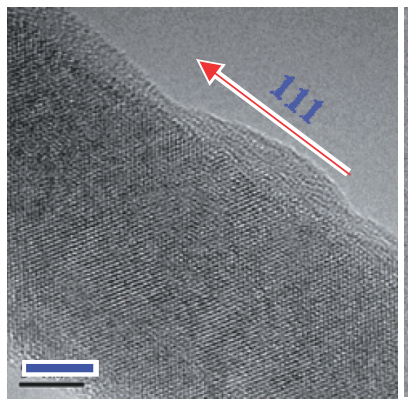

(c)

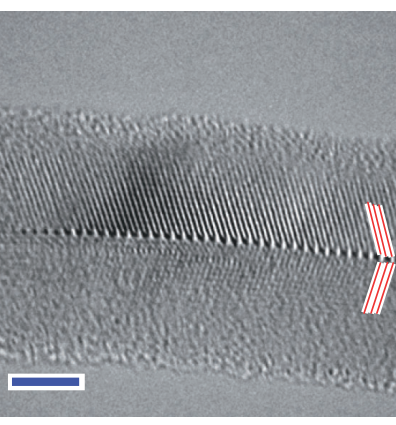

(b)

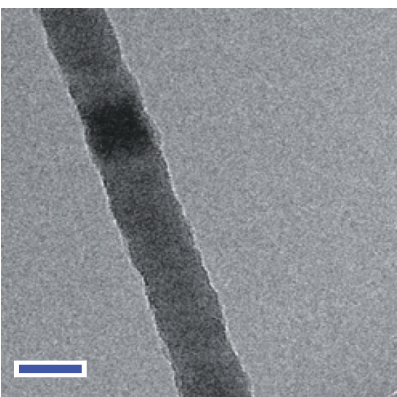

(d)
Fig. 5. High-resolution TEM images showing twin defects in SiNWs with diameters of (a) 18, (b) 20, and (c) $24 \mathrm{~nm}$, (d) low-resolution TEM image indicating zig-zag appearance of wires. Scale bar in (a)-(c) is $5 \mathrm{~nm}$ and in (d) is $20 \mathrm{~nm}$.

1) Y. Huang, X. Duan, and C. M. Lieber: Small 1 (2005) 142.

2) J. Goldberger, A. I. Hochbaum, R. Fan, and P. Yang: Nano Lett. 6 (2006) 973.

3) T. Kawano, H. Takao, K. Sawada, and M. Ishida: Jpn. J. Appl. Phys. 42 (2003) 2473.

4) J. F. Hsu, B. R. Huang, C. S. Huang, and H. L. Chen: Jpn. J. Appl. Phys. 44 (2005) 2626.

5) R. S. Wagner and W. C. Ellis: Appl. Phys. Lett. 4 (1964) 89.

6) E. I. Givargizove: J. Cryst. Growth 31 (1975) 20.

7) J. B. Hannon, S. Kodambaka, F. M. Ross, and R. M. Tromp: Nature 440 (2006) 69.

8) Y. Cui, L. J. Lauhon, M. S. Gudiksen, J. Wang, and C. M. Lieber: Appl. Phys. Lett. 78 (2001) 2214.

9) A. I. Hochbaum, R. H. R. Fan, and P. Yang: Nano Lett. 5 (2005) 457.

10) S. Hofmann, C. Ducati, R. J. Neill, S. Piscanes, A. C. Ferrari, J. Geng, R. E. Duin-Borkowaski, and J. Robertson: J. Appl. Phys. 94 (2003) 6005 .

11) S. Akhtar, A. Tanaka, K. Usami, Y. Tsuchiya, H. Mizuta, and S. Oda: Ext. Abstr. 5th Int. Conf. Si Epitaxy and Heterostructures, Marseille, 2007, p. 327.

12) S. Kodambaka, J. Terso, M. C. Reuter, and F. M. Ross: Phys. Rev. Lett. 96 (2006) 096105.

13) S. Sharma, T. I. Kamins, and R. S. Williams: Appl. Phys. A 80 (2005) 1225.

14) T.-K. Nguyen-Duc, N. Zakharov, G. Gerth, A. Milenin, L. Sokolov, and P. Werner: Ext. Abstr. 5th Int. Conf. Si Epitaxy and Heterostructures, Marseille, 2007, p. 118. 